\title{
Novel silane based cross-linkers for preparation of methyl methacrylate gels
}

\author{
Javaherian Naghash Hamid, "Mir Garshasb
}

*Department of Chemistry, Islamic Azad University, Shahreza Branch P.O. Box 311 86145, Shahreza, Isfahan, I. R. Iran; fax: 0098-321-3211018; e-mail: Javaherian@iaush.ac.ir.

(Received: 02 January, 2010; published: 08 November, 2010)

\begin{abstract}
Dimethylsilanediyl)bis(oxy)bis(ethane-1,2-diyl)bis(2-methylacrylate) (Type A cross-linker), (2,2'-(methyl) (phenyl) silanediyl)bis(oxy) bis (ethane-1,2diyl)bis(2-methylacrylate)) (Type B cross-linker), and (2,2'-(diphenylsilanediyl)bis (oxy)bis(ethane-1,2-diyl)bis(2-methylacrylate)) (Type C cross-linker) three novel cross-linkers, (divinyl monomers), containing silanes and two methacrylates group (Si-DVM) were prepared by the condensation of 2-hydroxyethyl methacrylate (HEMA) with dichlorodimethyl, (DCDM) dichloromethyl phenyl (DCMP) and dichlorodiphenyl silane (DCDPS) in the presence of triethylamine (TEA). With these cross-linkers, methyl methacrylate, (MMA) can copolymerize by free-radical cross-linking copolymerization in toluene at a total monomer concentration of 3 $\mathrm{molL}^{-1}$ and at $70{ }^{\circ} \mathrm{C}$. The experimental results show that increasing of Si-DVM concentration resulted in a decrease in gel point and swelling degree and an increase in conversion percent and weight fraction of the gels. The obtained crosslinkers were characterized by ${ }^{1} \mathrm{H}-\mathrm{NMR}$ and ${ }^{13} \mathrm{C}-\mathrm{NMR}$ spectroscopy and structural characteristics of the gels were examined by using equilibrium swelling in toluene solvent, gel fraction and Fourier-transform infrared (FTIR) analysis. The morphology of the copolymers was also investigated by Scanning electron microscopy (SEM).

Keywords: silicones; cross-linking; copolymerization; gel.
\end{abstract}

\section{Introduction}

There are many chemical and biomedical applications such as optics, electronics, mechanics and electrochemistry which require polymer gels with excellent absorption and mechanical properties [1-16]. These materials are prepared mainly by freeradical copolymerization of monovinyl (MVM) and divinyl monomers (DVM) in a suitable solvent [17-22]. On the other hand, an interesting family of nanocomposites is obtained from copolymerization reactions between siloxane and polymethylmethacrylate (PMMA) precursors, which lead to covalently bonded inorganic and organic nanophases. This allows the synthesis of bulk materials with adjustable transparency, refractive index and hardness [23, 24]. Because of such interesting properties, these materials have been used as lenses, coatings on commercial glasses to increase elastic modulus and decrease brittleness [25] and for micropatterning of thin-channel wave-guides [26, 27]. The application and industrial processing of these materials strongly depends on their rheological properties, which are determined by the interactions and motions of the constituent structural units, such as polymeric chains, aggregates, etc. The understanding of the correlations between rheological properties and nanostructural features of gelling systems is one of the great challenges of polymer chemistry that would certainly contribute to the molecular design of new materials. Depending on the type of monomer structure, it 
may swell in organic solvents and/or in water. The radical copolymerization of various silicone functional monomers and synthesis of new functional polymers with given structures and important properties have attracted considerable interest based on the improvement of properties and economical advantages. The major aim of this study was to synthesize new silicone containing cross-linkers for MMA gel preparations. In this article, the effort has been to elucidate the effects of silicone containing crosslinkers on free-radical cross-linking copolymerization of MMA networks. For this purpose, evaluation of the weight fraction of gel and its equilibrium degree of swelling, conversion of monomer, and gel point were examined as functions of the reaction time and variations in silicone concentration.

\section{Results and discussion}

The structures of Types A, B and C cross-linkers and PMMA copolymers before the gel point were confirmed through FTIR, ${ }^{1} \mathrm{H}-\mathrm{NMR}$ and ${ }^{13} \mathrm{C}-\mathrm{NMR}$ spectroscopies and are shown in Figure (1-7), respectively.

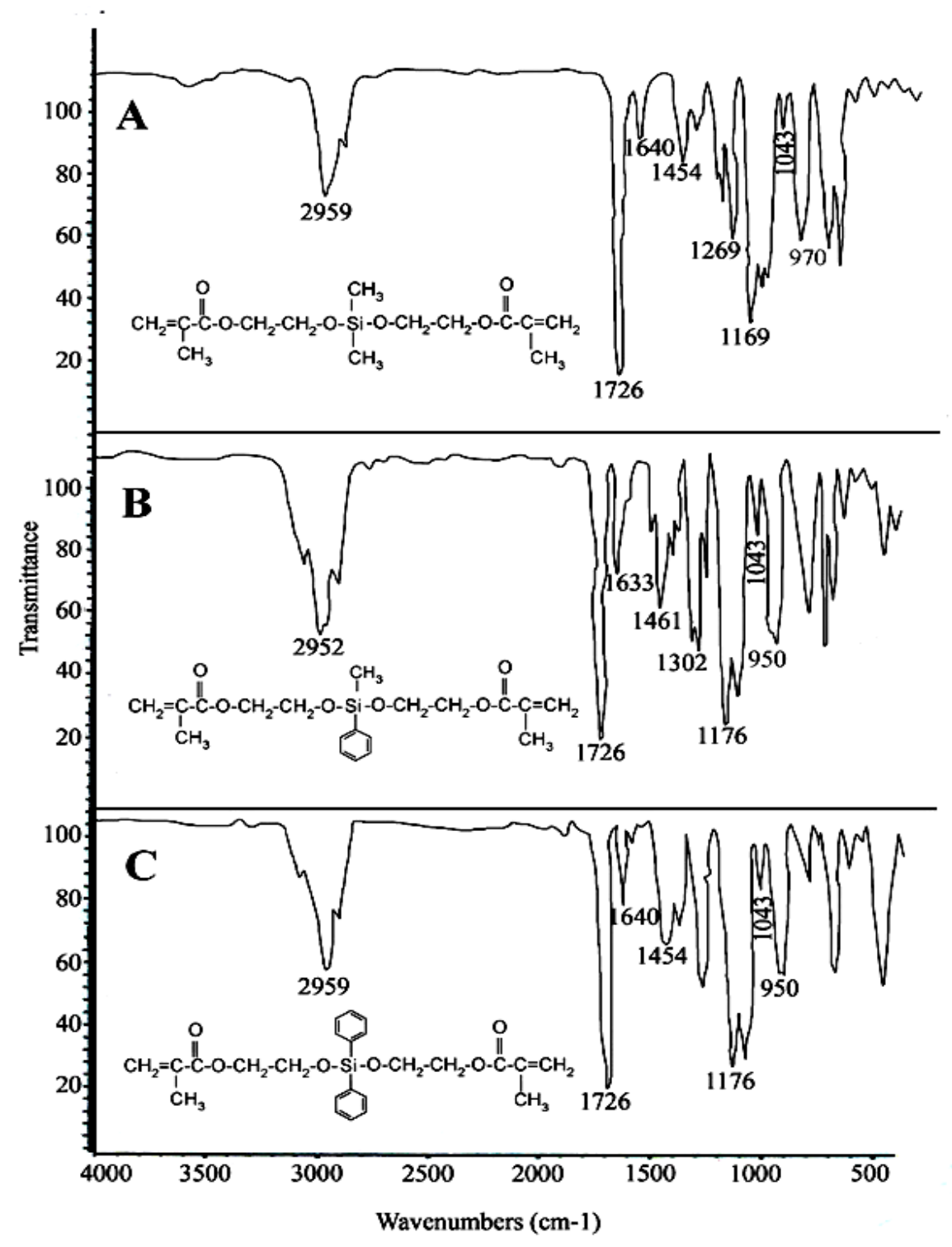

Fig. 1. FTIR spectrum of A: (Type A cross-linker), B: (Type B coss-linker) and C: (Type C cross-linker). 


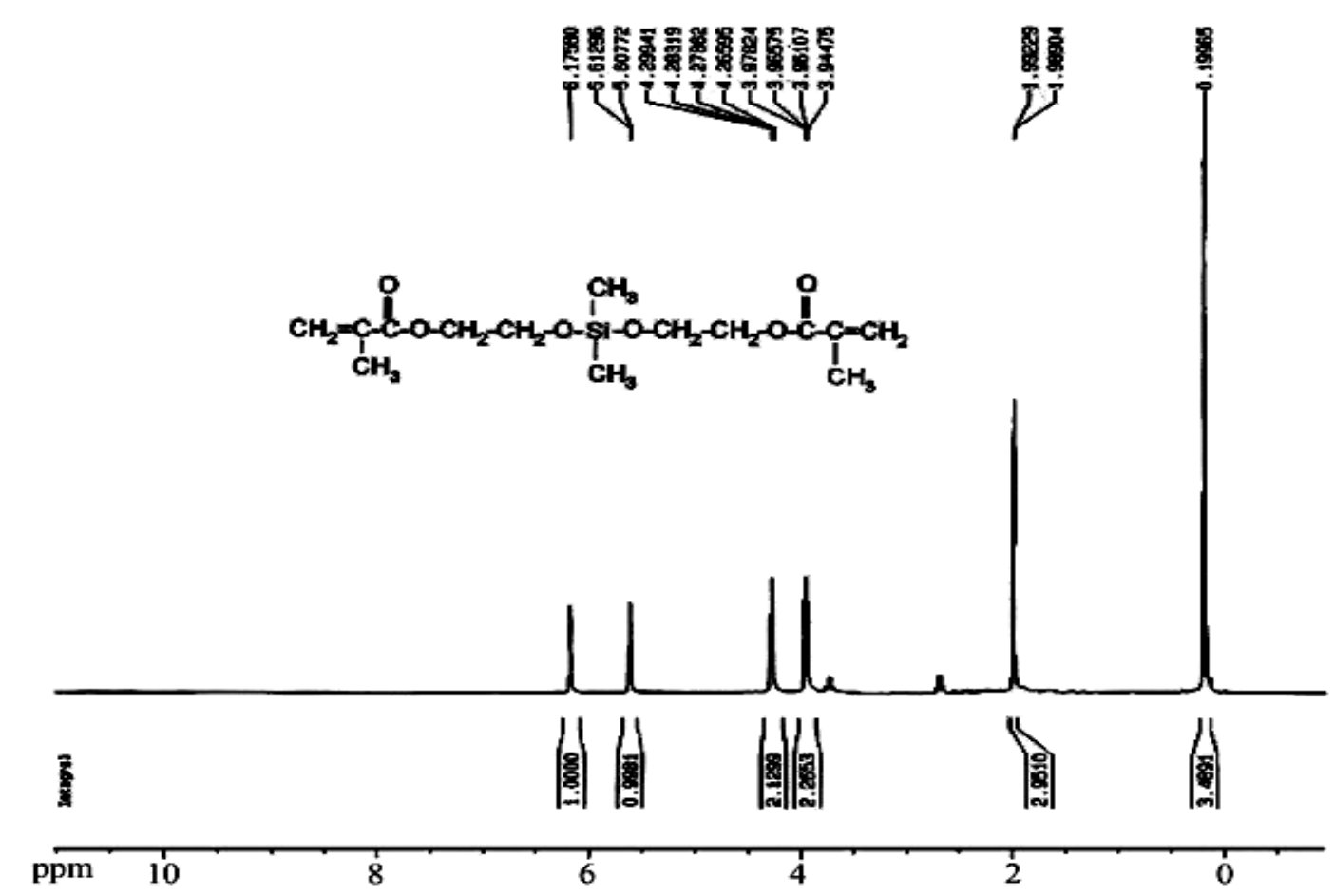

Fig. 2. ${ }^{1} \mathrm{H}-\mathrm{NMR}$ spectrum of Type A cross-linker.
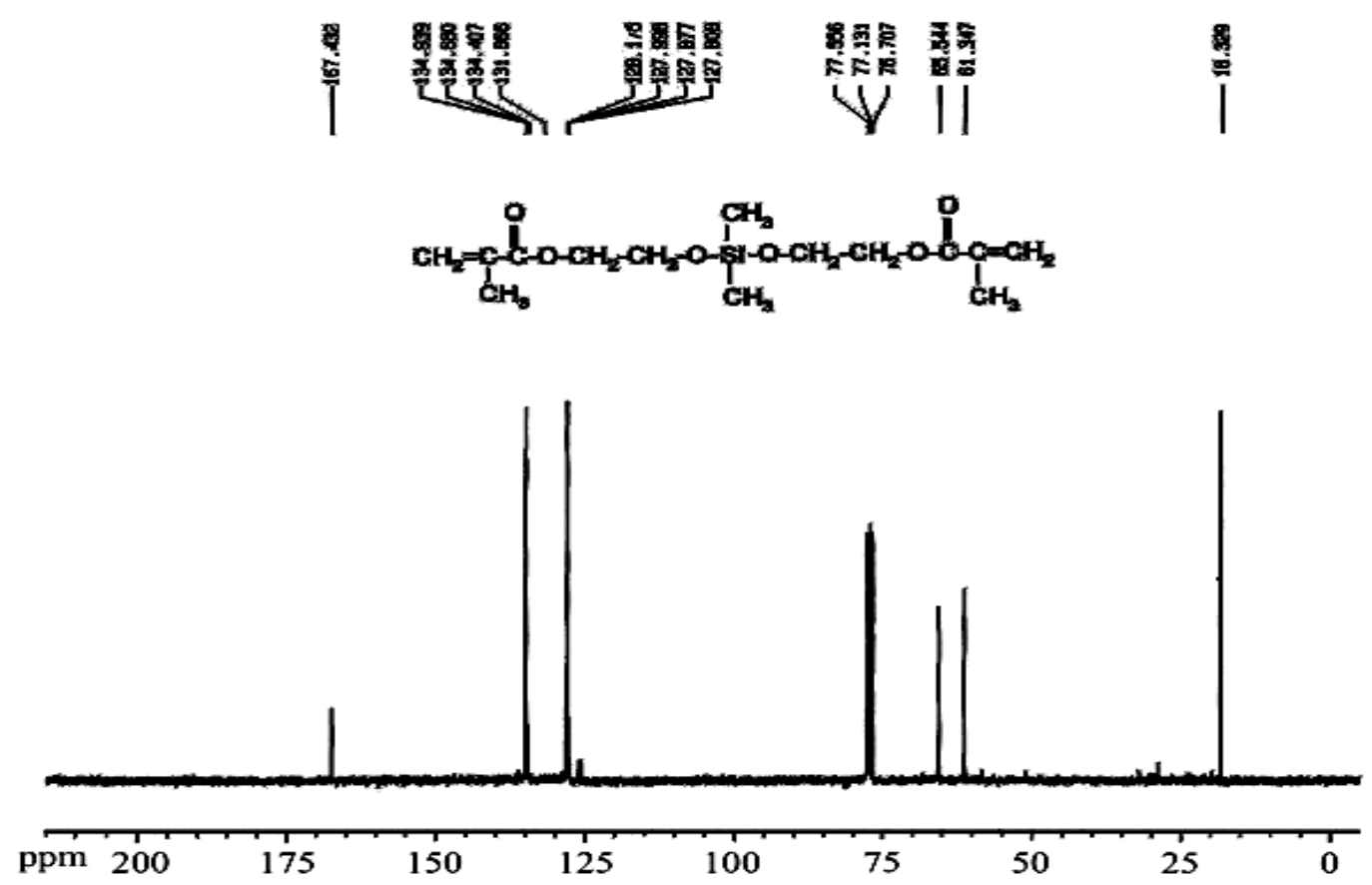

Fig. 3. ${ }^{13} \mathrm{C}-\mathrm{NMR}$ spectrum of Type A cross-linker.

Figure 1 shows the FTIR spectrum of (A), Type A, (B), Type B and (C), Type C crosslinkers. The characteristic bands due to $\mathrm{Si}-\mathrm{CH}_{3} 2959,1043$ and $840, \mathrm{~cm}^{-1}$ and $\mathrm{Si}-\mathrm{O}-$ $\mathrm{Ph} 950 \mathrm{~cm}^{-1}$ of silicone units were assigned the $\mathrm{A}, \mathrm{B}$, and $\mathrm{C}$ spectra. The bands due to $\mathrm{C}=\mathrm{O}$ stretching for carbonyl at 1726 and vinyl $1454 \mathrm{~cm}^{-1}$ are also characteristic absorptions of them respectively $((A, B$, and $C$ (spectra)). Figure 2 represents the ${ }^{1} \mathrm{H}$-NMR spectrums of Type A cross-linker where the signals of the $-\mathrm{CH}_{2}$ resonance 
of vinyls $(5.50-6.25 \mathrm{ppm})$ and the $-\mathrm{oCH}_{2}-\mathrm{CH}_{2}$ resonance $3.75-4.50$, the $-\mathrm{CH}_{3}$ resonance 1.80 and $\mathrm{Si}-\mathrm{CH}_{3} 0.08$ ppm in siloxane segments are observed.
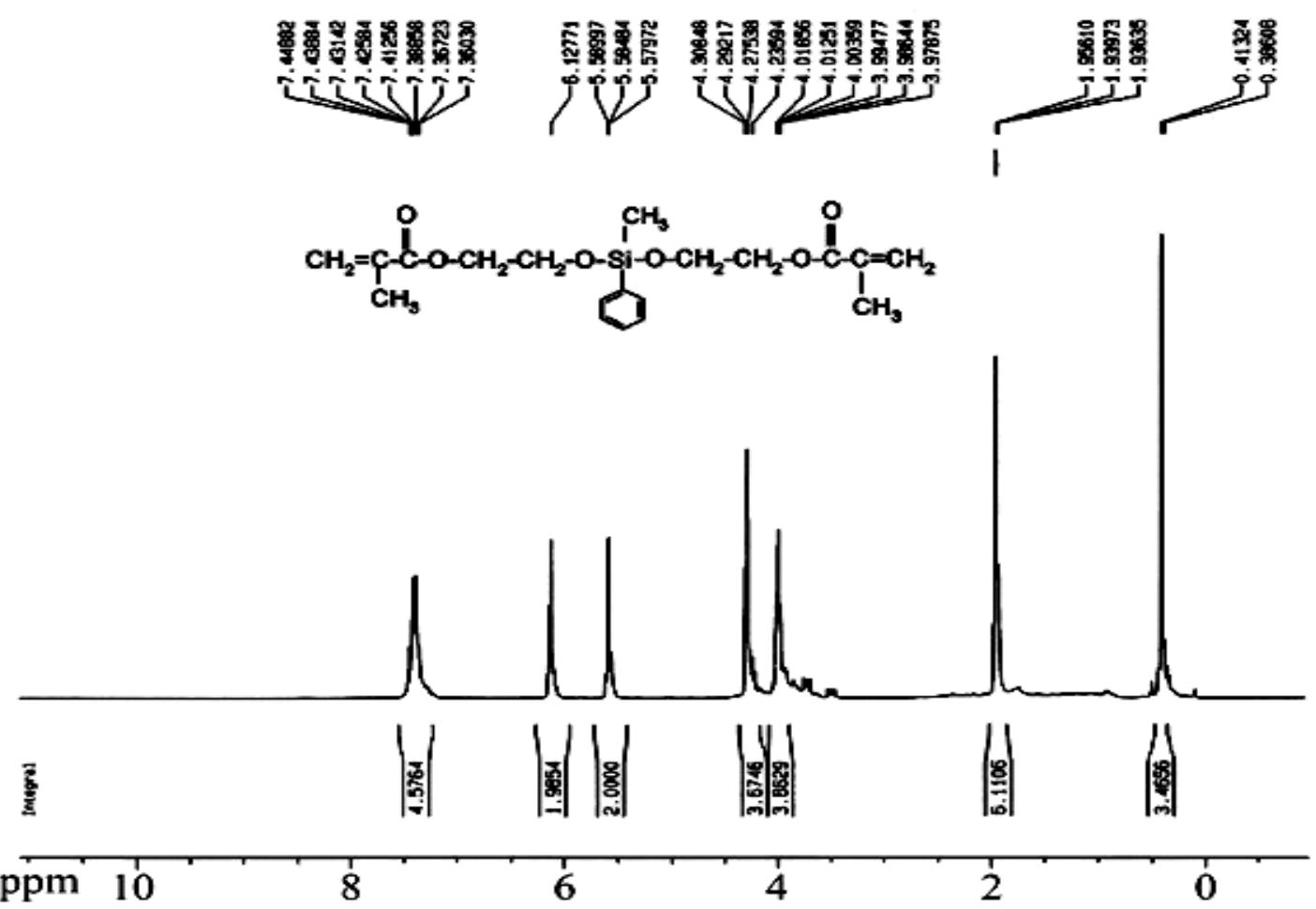

Fig. 4. ${ }^{1} \mathrm{H}-\mathrm{NMR}$ spectrum of Type B cross-linker.
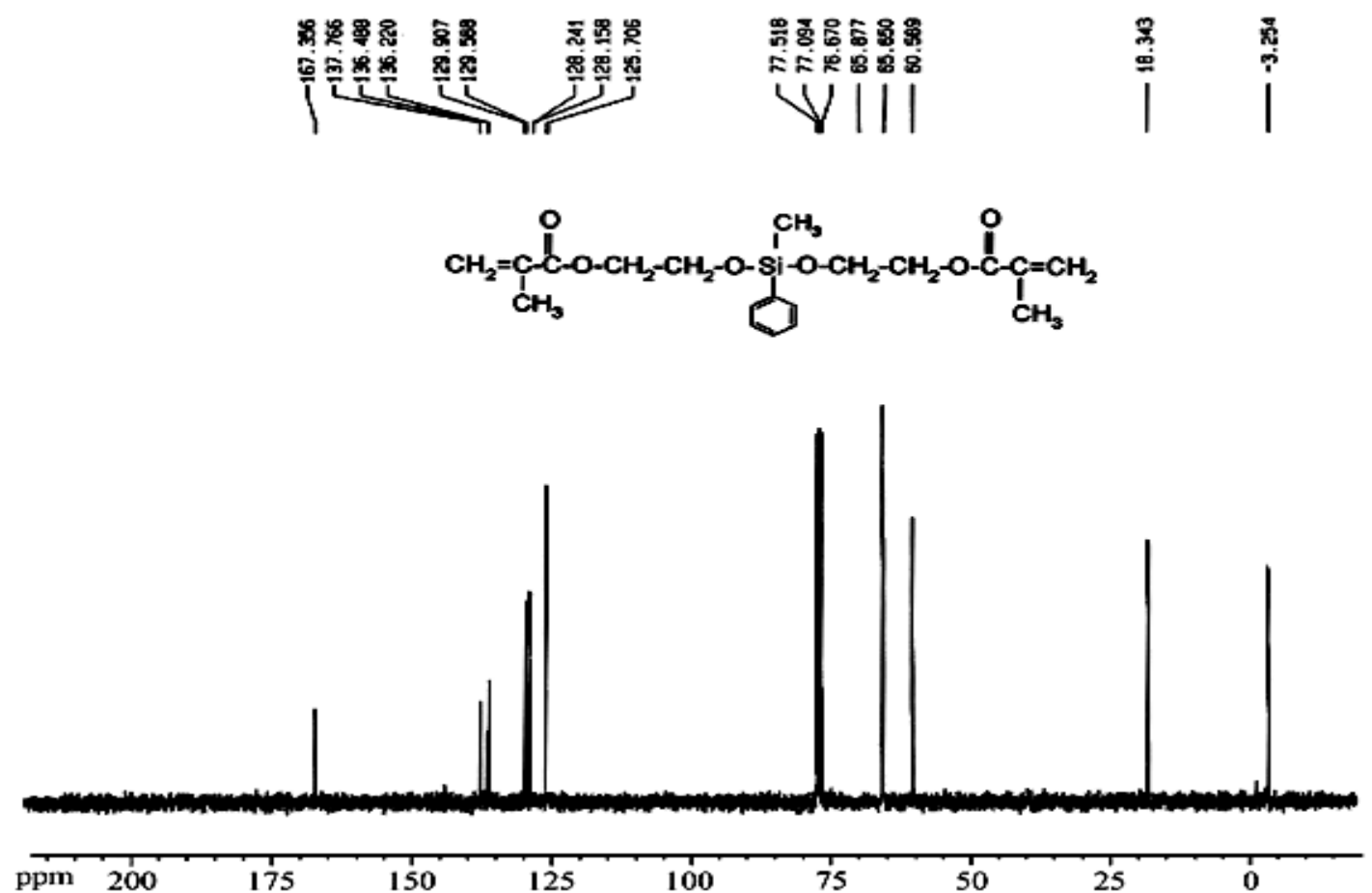

Fig. 5. ${ }^{13} \mathrm{C}-\mathrm{NMR}$ spectrum of Type B cross-linker. 


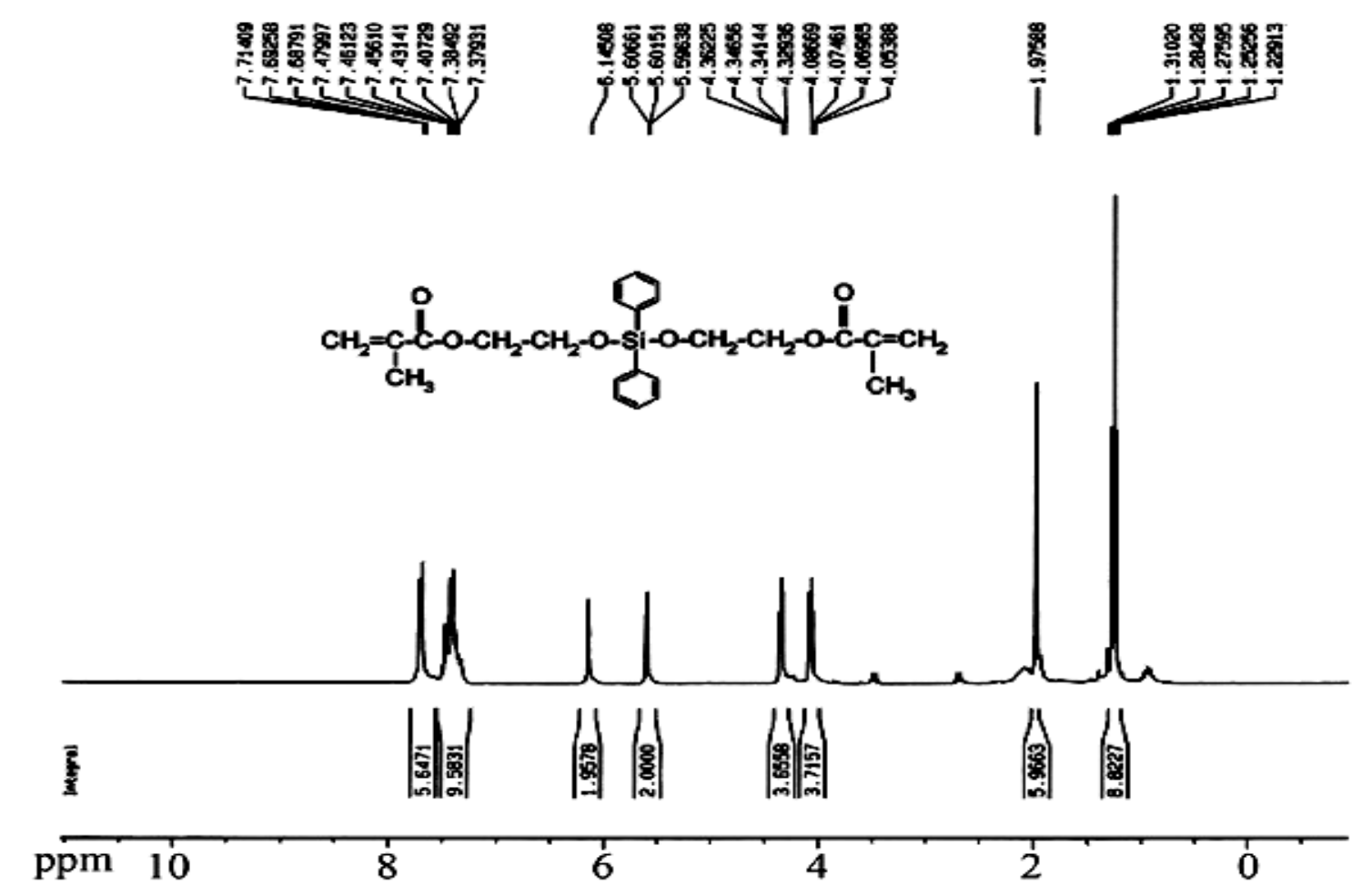

Fig. 6. ${ }^{1} \mathrm{H}-\mathrm{NMR}$ spectrum of Type $\mathrm{C}$ cross-linker.
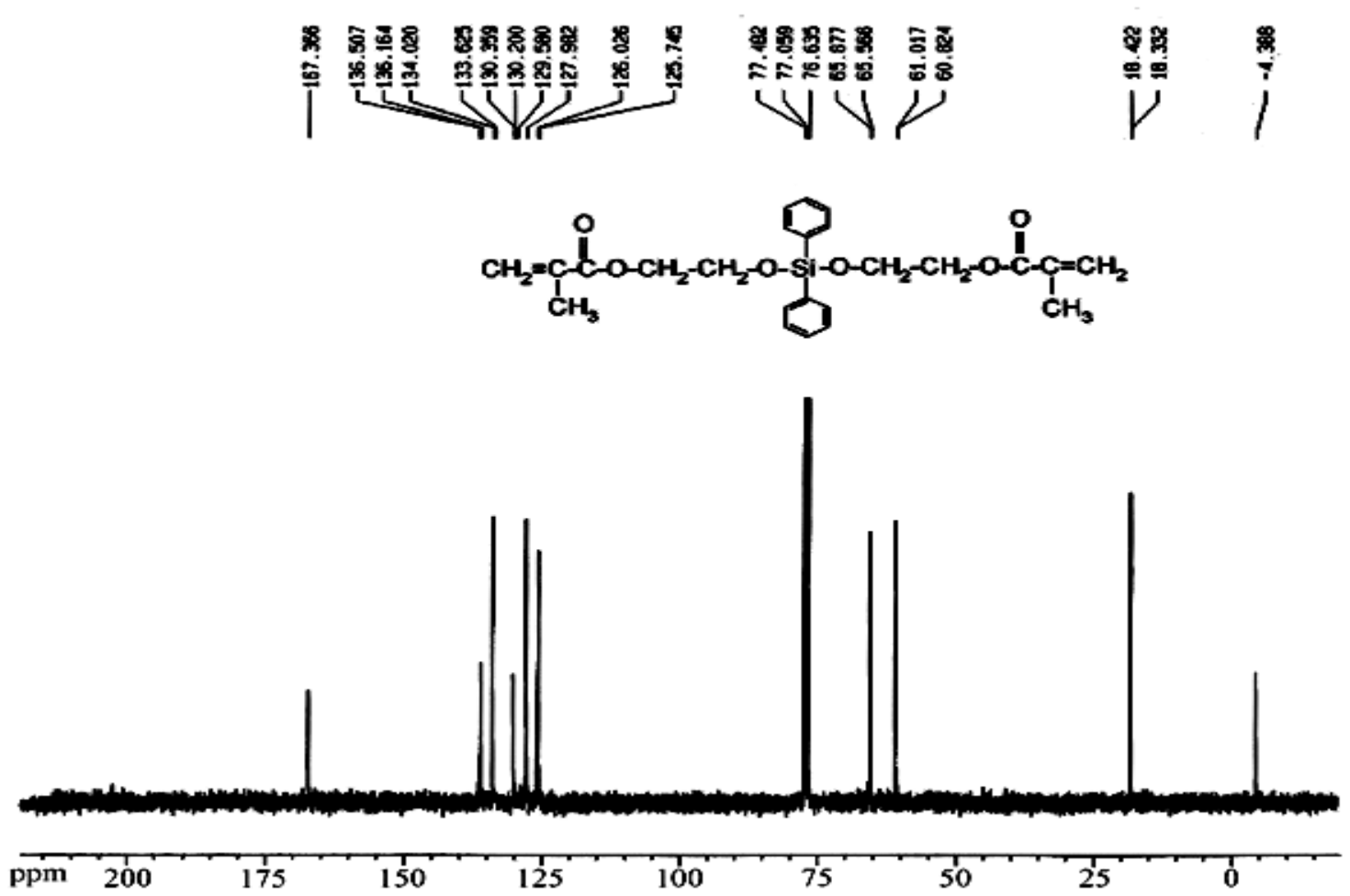

Fig. 7. ${ }^{13} \mathrm{C}-\mathrm{NMR}$ spectrum of Type $\mathrm{C}$ cross-linker.

Figure 3 indicates the ${ }^{13} \mathrm{C}$-NMR spectrum of Type $\mathrm{A}$ cross-linker. The number of carbons of this type of cross-linker is compatible with the number of spectrums. Figure 4 illustrates the ${ }^{1} \mathrm{H}$-NMR spectrums of Type $\mathrm{B}$ cross-linker, where the signals of the $-\mathrm{CH}_{2}$ resonance of vinyls $(5.50-6.25 \mathrm{ppm})$ and the $-\mathrm{oCH}_{2}-\mathrm{CH}_{2}$ resonance 3.80- 
4.25, the $-\mathrm{CH}_{3}$ resonance 2 and $\mathrm{Si}-\mathrm{CH}_{3} 0.30$ and aromatic protons 7-8 ppm in siloxane segments are observed. Figure 5 indicates the ${ }^{13} \mathrm{C}$-NMR spectrum of Type $\mathrm{B}$ cross-linker. The number of carbons in this type is also compatible with the number of spectrums. Figure 6 illustrate the ${ }^{1} \mathrm{H}$-NMR spectrums of Type $\mathrm{C}$ cross-linker, where the signals of the $-\mathrm{CH}_{2}$ resonance of vinyls $(5.50-6.10 \mathrm{ppm})$ and the $-\mathrm{oCH}_{2}-\mathrm{CH}_{2}$ resonance 4-4.4, the $-\mathrm{CH}_{3}$ resonance 2 and $\mathrm{Si}_{-} \mathrm{CH}_{3} 1.2$ and aromatic protons 7-8 $\mathrm{ppm}$ in siloxane segments are observed. Finally, Figure 7 indicates the ${ }^{13} \mathrm{C}-\mathrm{NMR}$ spectrum of the same type cross-linker. The number of carbons in the Type $\mathrm{C}$ crosslinker is compatible with the number of spectrums. The expected structures of the divinyl monomers are confirmed by these figures.

\section{Effects of Types A, B and C cross-linkers concentrations on the MMA gel properties}

Increasing Types $\mathrm{A}, \mathrm{B}$ or $\mathrm{C}$ cross-linkers concentrations resulted in an increase in the weight fraction of gel and decrease in the swelling degree (Figure 8A). Also, the conversion percent showed a drastic increase while the gel point showed a decrease (Figure 8B).

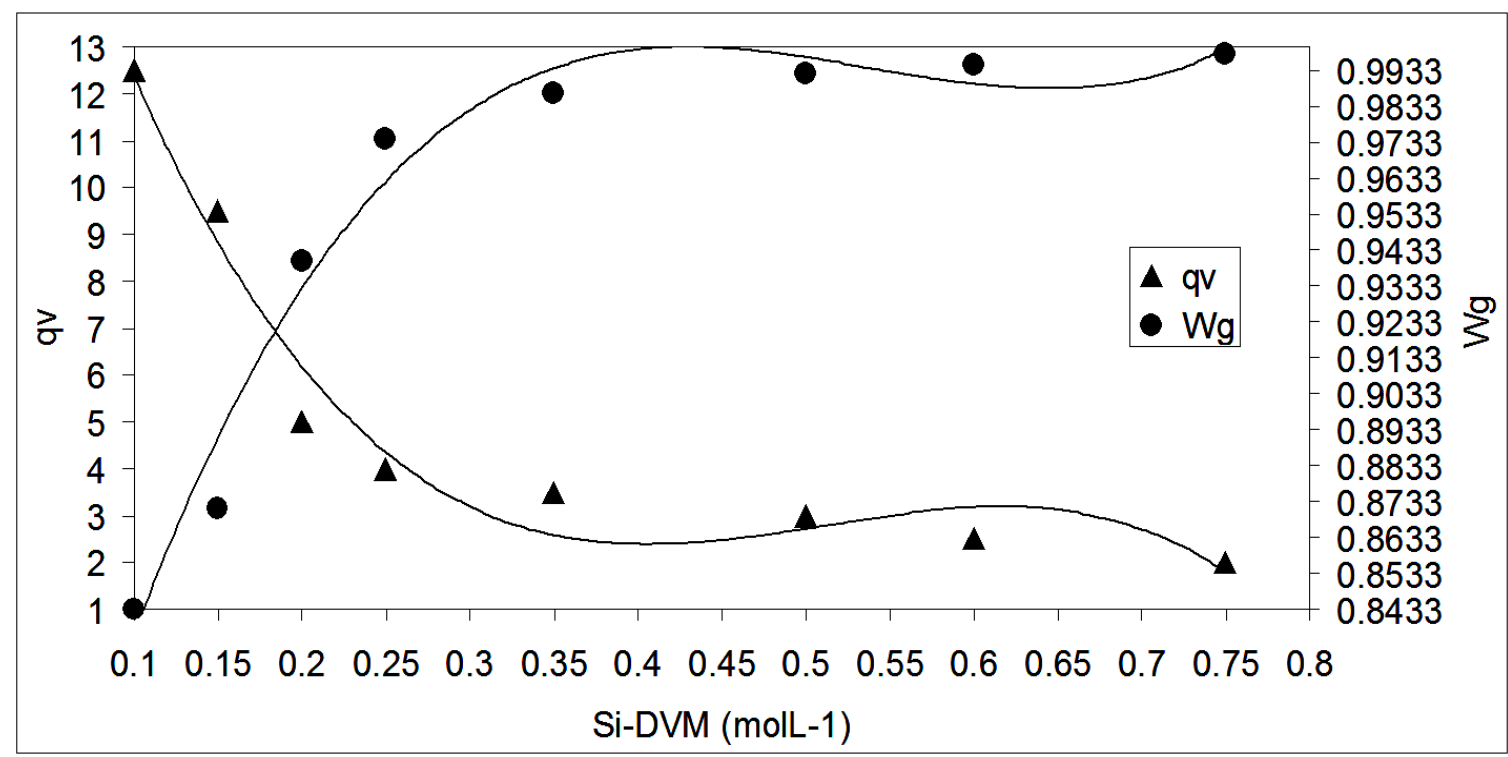

Fig. 8A. Weight fraction of gel $(\bullet) W_{g}$ and the equilibrium volume swelling ratio of the gel $(\boldsymbol{\Delta}) q_{v}$ plotted as functions of the Si-DVM concentration for MMA copolymerization in toluene at $70{ }^{\circ} \mathrm{C},[\mathrm{M}]_{0}=3 \mathrm{molL}^{-1}$.

It is well known that four types of reactions are involved in free radical polymerization, namely initiation, propagation, termination and chain transfer [28]. Also, it should be noted that the free radical cross-linking copolymerization system involves three types of vinyl groups: those on vinyl and divinyl monomers (DVM) and those on polymer chains, ie pendant $[22,28]$. Accordingly, the polymerization system can be considered as a special case of terpolymerization in which one of the vinyl groups (pendant vinyls) is created during the course of the reaction when the vinyl on the divinyl monomer reacts. The formed pendant vinyl groups can then react by cyclization, cross linking or multiple cross linking reactions, or remain pendant. With cyclization, a cycle is formed when the macroradical attacks the pendant vinyl group in the same kinetic chain, while with multiple cross-linking is formed if the radical attacks the pendant double bonds on other chains already chemically connected to 
the growing radical $[29,30]$ It should be noted that cyclization and multiple crosslinking have been redefined as primary and secondary cyclization, respectively [31]. On the other hand, when a three-dimensional network is formed, the reactive species chemically bound to the network, such as the pendant double bonds and free radical centres, have extremely small diffusion coefficients which can significantly suppress their reactivity which is based on the swelling measurement and theoretical discussions, even to the extent that they may be considered to be trapped and unavailable for reactions.

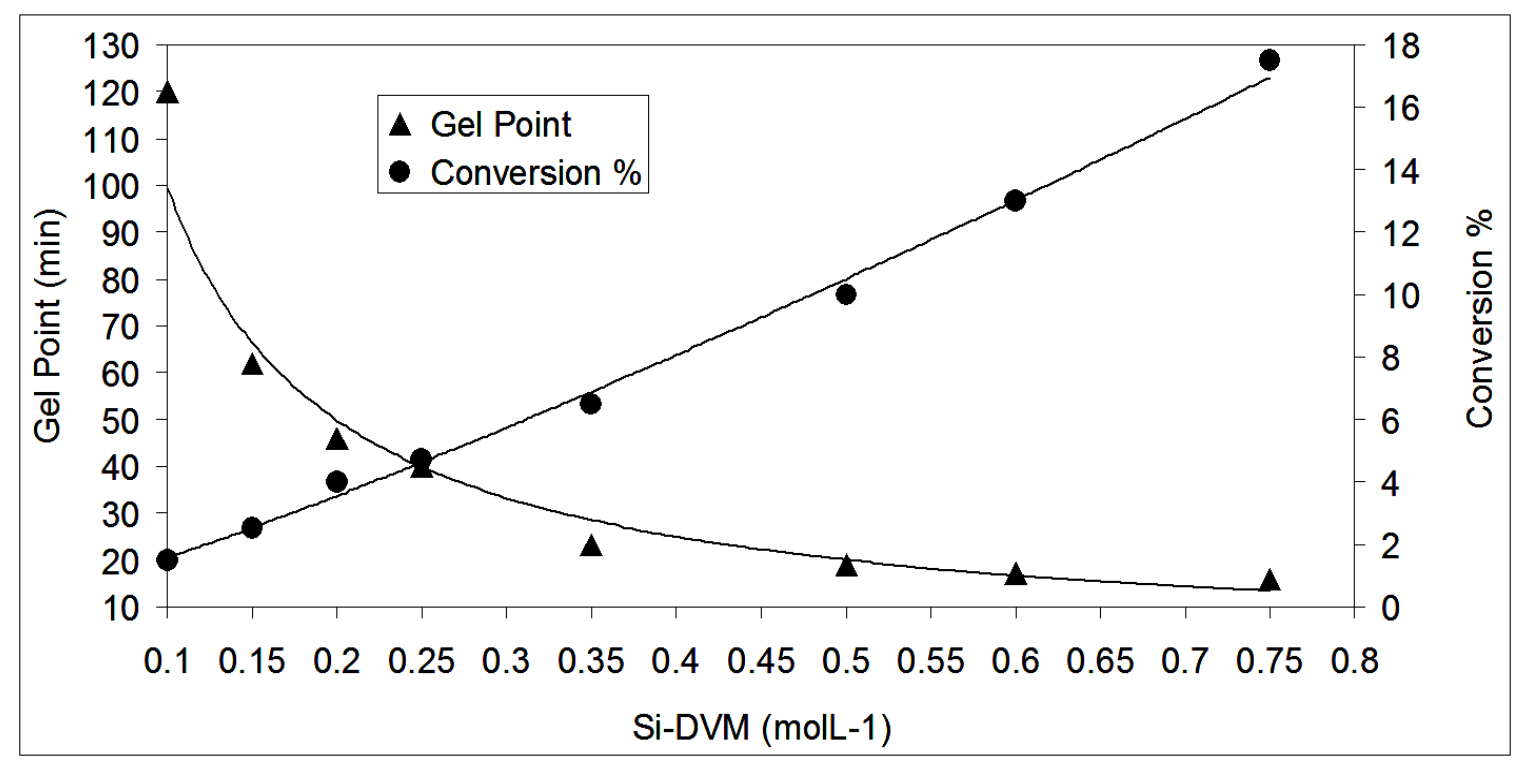

Fig. 8B. Monomer conversion and the gel point shown as function of the Si-DVM concentration for MMA copolymerization in toluene at $70{ }^{\circ} \mathrm{C},[\mathrm{M}]_{0}=3 \mathrm{molL}^{-1}$, are shown as $(\bullet)$ conversion $\%$ and $(\boldsymbol{\Lambda})$ gel point.

\section{Effects of Types $A, B$ or $C$ cross-linkers concentrations on reaction rate}

Although copolymerization of MMA with EGDM has been well established [28-36], its copolymerization in the presence of Types of $A, B$ or $C$ cross-linkers have not been reported. It is possible that during cross-linking copolymerization process this monomer will make part of the polymer network. (Figure $8 \mathrm{C}$ ) shows the effect of different cross-linkers Types ( $\mathrm{A}, \mathrm{B}$ and $\mathrm{C}$ ) concentrations on the monomer conversion and (Figure $8 \mathrm{D}$ ) shows the effect of Type A cross-linker concentration versus time respectively, where the total monomer concentration was fixed at a $3 \mathrm{molL}^{-1}$ and at $70{ }^{\circ} \mathrm{C}$. These Figures show that the rate of reaction changes with the silicone types, and according to (Figure $8 \mathrm{C}$ ), the reaction rate decreases from Type A to Type $\mathrm{C}$ cross-linkers containing polymethyl methacrylate copolymer and the maximum rate is obtained by Type A cross-linker containing copolymers. (Figure $8 \mathrm{D}$ ) shows that the reaction rate of Type $A$ cross-linker containing polymer is increased by increasing Type A cross-linker and the same results were obtained for the other silane compounds. According to the primary and secondary cyclization described in the previous section, the first macroradicals formed were highly intramolecularly crosslinked, and should thus exhibit compact structures. The increase in silicone content increases the compactness of the structures formed and this resulted in a decrease in the mobility of chain segments and therefore decreased the diffusion - controlled termination of radicals owing to steric reasons. Furthermore, the rates of propagation 
and consequently copolymerization in a radical copolymerization reaction are related to the termination rate constant. As the amount of Type A cross-linker increased, it acted as a chain transfer agent and the rate of polymerization increased. Although these silane compounds have the same vinyl groups, their other substituents are different. For this reason, the steric hindrance and electronic influences of these groups are not the same, and therefore the reactivity of the corresponding silane groups in MMA copolymers does not show the same effect. In the case of Type C cross-linker, the phenyl groups are sterically hindered and increased the bulkiness around the centre of the reactions.

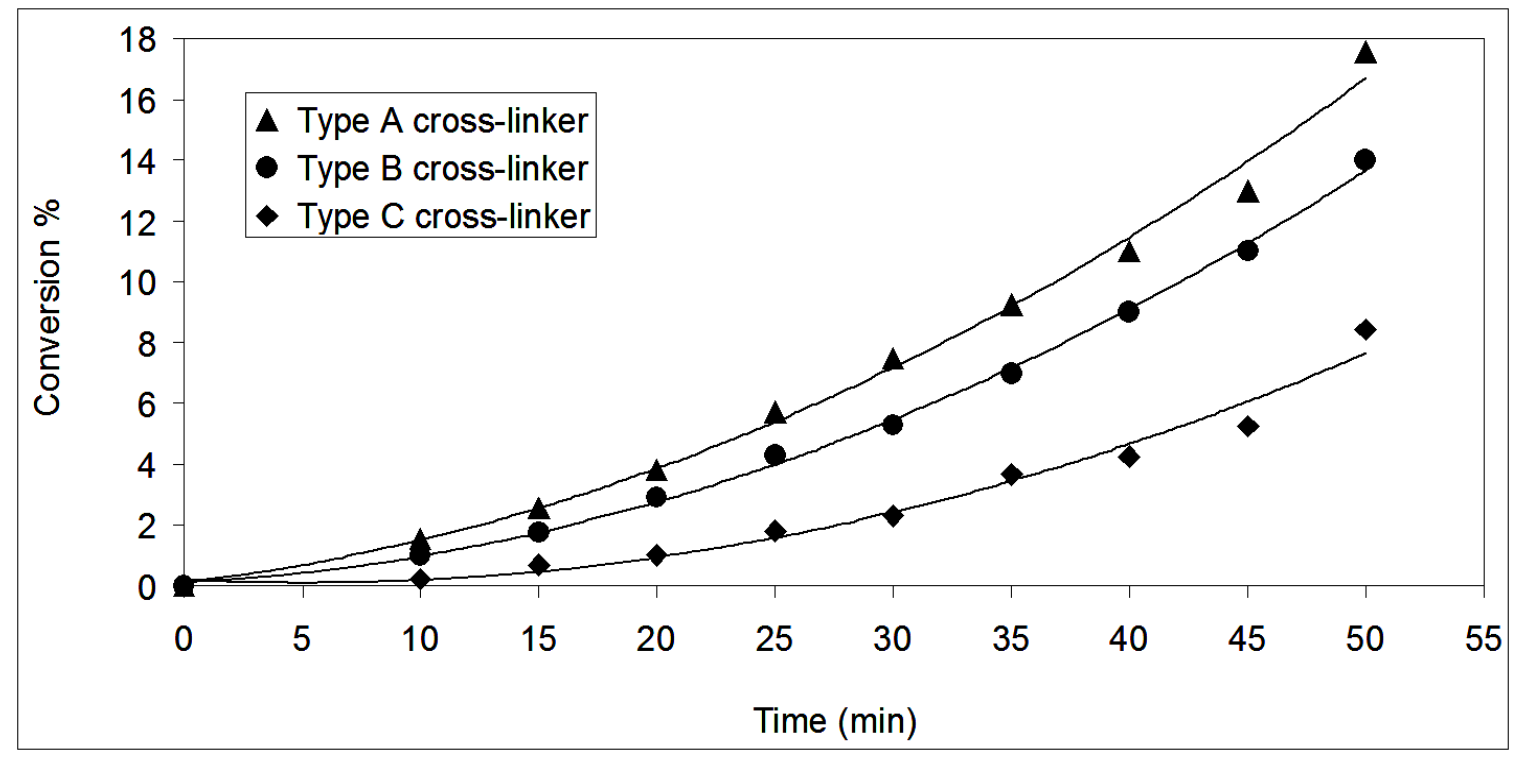

Fig. 8C. The effect of cross-linkers types on the monomer conversion versus time histories at $(\mathbf{\Delta})$ Type A cross-linker, $(\bullet)$ Type B cross-linker, $(\bullet)$ Type C cross-linker, $[\mathrm{M}]_{0}=3 \mathrm{molL}^{-1}$, at $70{ }^{\circ} \mathrm{C}$.

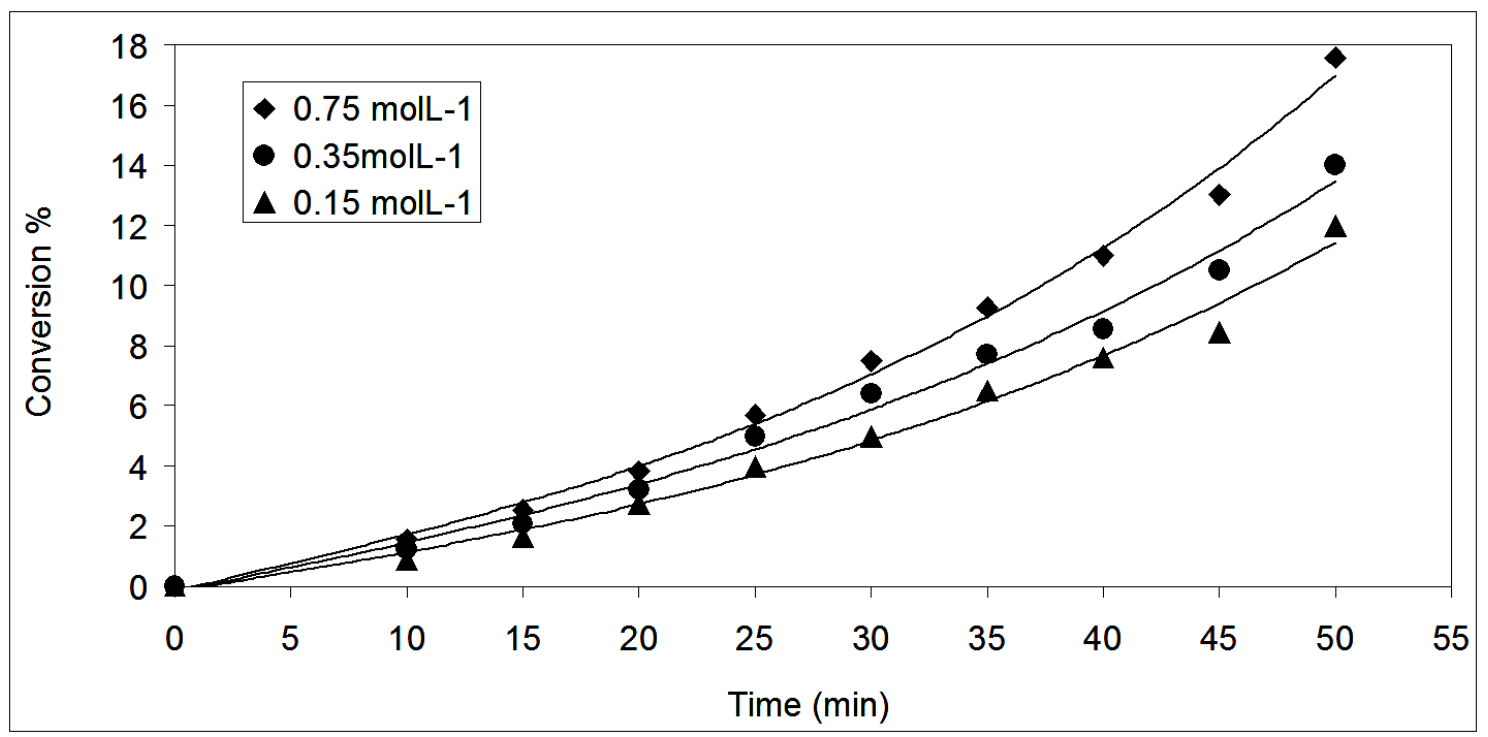

Fig. 8D. The effect of initial Type A cross-linker concentration on monomer conversion versus time histories at $(\boldsymbol{\Delta}) 0.15 ;(\bullet) 0.35$ and $(\bullet) 0.75, \mathrm{molL}^{-1},[\mathrm{M}]_{0}=3$ $\mathrm{molL}^{-1}$, at $70^{\circ} \mathrm{C}$ 
On the other hand, phenyl is an electron-withdrawing group and therefore destabilized the reaction. The overall effect of phenyl groups is to decrease the rate of reactions. In the case of Type A, or Type B cross-linkers the alkoxy groups are electron donating and can stabilize the intermediate in the reactions, and consequently the rate of reaction increased.

\section{Morphology of polymer gels}

The morphologies of MMA/EGDM, MMA/Type A cross-linker, MMA/Type B crosslinker and MMA/Type $C$ cross-linker copolymers were examined by SEM and the images are shown in Figure 9 (A, B, C and D) respectively.

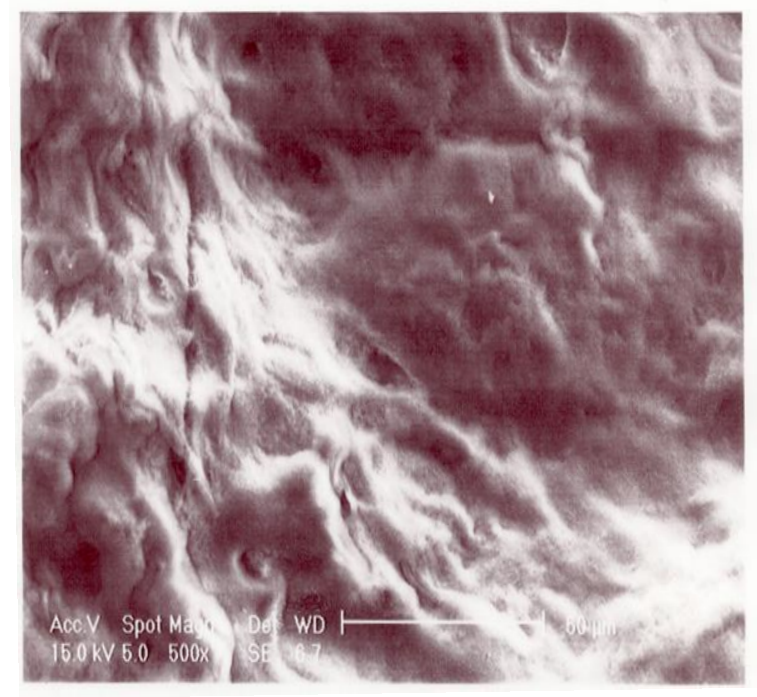

(A)

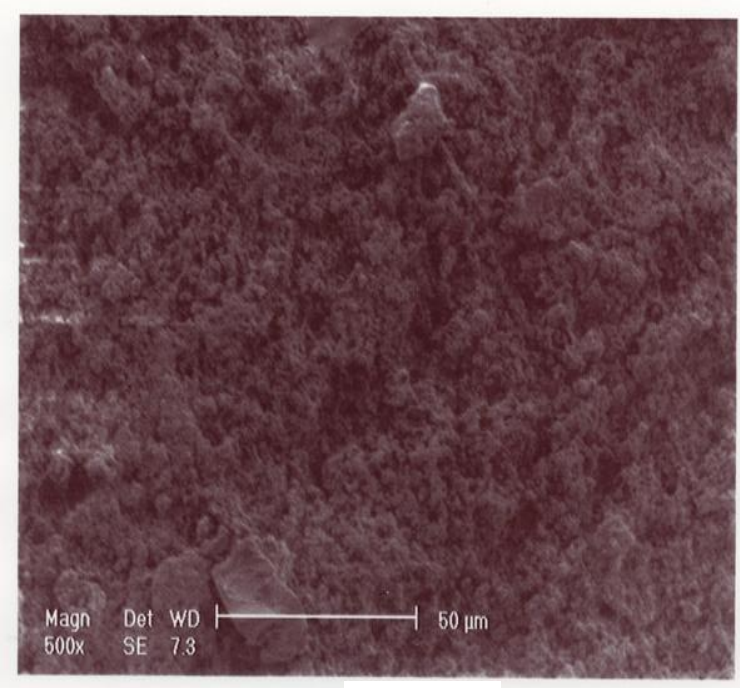

(C)

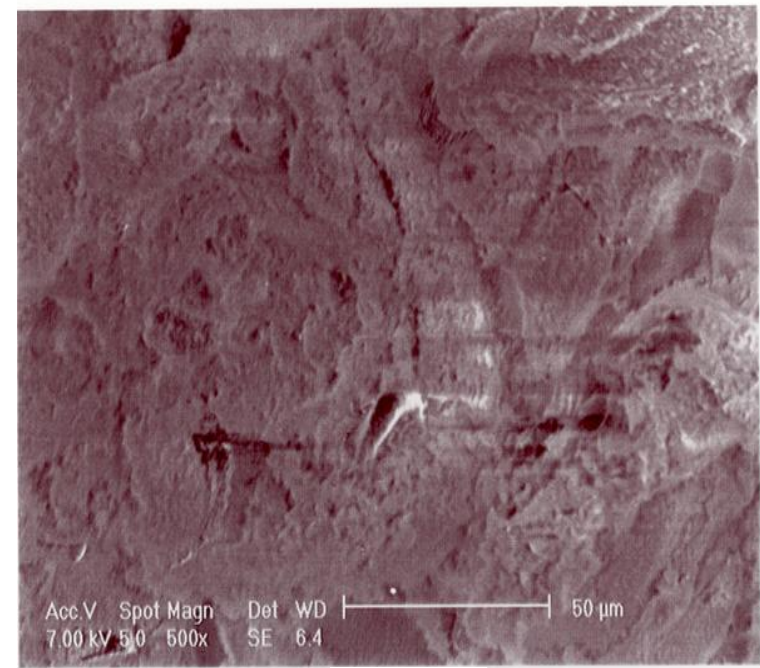

(B)

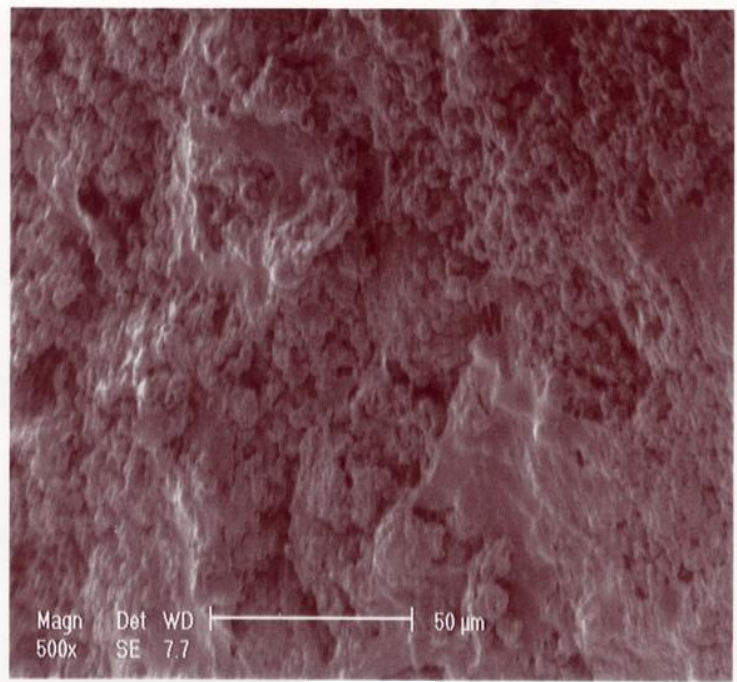

(D)

Fig. 9. SEM pictures of (A), MMA/EGDM, (B) MMA/Type A cross-linker, (c) MMA/Type B cross-linker and(D) MMA/Type $C$ cross-linker copolymers at $70{ }^{\circ} \mathrm{C},[\mathrm{M}]$ 。 $=3 \mathrm{molL}^{-1}$.

These images show the surface of MMA/EGDM copolymers without Si-DVM considerably different from the others copolymers with Si-DVM. This difference can 
be due to the presence of silane compounds. Also, the Figure $9 \mathrm{~B}$ exhibits a dense microstructure with many loose texture morphology. Figure 9 ( $C$ and $D$ ) show a homogeneous morphology, with the presence of a lot of cracks probably due to the solvent evaporation. As a result, the presence of silane compounds and solvent evaporation lead to achievement of lot of porosity on the surfaces of the copolymers.

\section{Conclusions}

Three novel cross-linkers, (divinyl monomers), containing silanes and two methacrylate groups (Si-DVM) were prepared by the condensation of 2-hydroxyethyl methacrylate (HEMA) with dichlorodimethyl, (DCDM) dichloromethyl phenyl (DCMP) and dichlorodiphenyl silane (DCDPS) in the presence of triethylamine (TEA). With these cross-linkers, methyl methacrylate, (MMA) can copolymerize by free-radical cross-linking copolymerization in toluene at a total monomer concentration of $3 \mathrm{molL}^{-1}$ and at $70{ }^{\circ} \mathrm{C}$. The following results were obtained:

1- FTIR, ${ }^{1} \mathrm{H}$-NMR and ${ }^{13} \mathrm{C}$-NMR spectroscopy analysis showed that silicone segments are present in the copolymer structures.

2-Increasing the Types of $\mathrm{A}, \mathrm{B}$, or $\mathrm{C}$ cross-linker concentration resulted in an increase in the weight fraction of gel and decrease in the swelling degree. Also, the conversion percent showed a drastic increase while the gel point showed a decrease.

3- The presence of silicone moieties in the MMA/Types of $A, B$ or $C$ cross-linker copolymers causes a heterogeneous morphology with the existence of a lot of porous on the surface of the samples.

\section{Experimental}

\section{Materials}

The monomer, methyl methacrylate (MMA, Merck Chemicals Co., Darmstadt, Germany) was washed with $10 \%$ aqueous potassium hydroxide to remove inhibitor, followed by several washings with deionized water. After drying successively with anhydrous sodium sulfate and $4 \mathrm{~A}^{\circ}(40 \mathrm{~nm})$ molecular sieves, it was distilled under reduced pressure. The middle fraction was then collected. Dichlorodimethylsilane (DCDMS) and dichloromethyl phenyl silane (DCMPS), (Merck Chemicals Co., Darmstadt, Germany) were used without further purification. Dichlorodiphenyl silane (DCDPS, Aldrich, Chemie, GmbH \& KG-Steinem, Germany) was used as received. 2-Hydroxyethyl methacrylate (HEMA) was purchased from Merck Chem. Co. and was distilled under reduced pressure. The initiator, 2/2-azobis(2-methyl-propionitrile) (AIBN, Merck, Chem. Co.), was recrystallized three times from absolute methanol, followed by drying in a vacuum oven at room temperature. The polymerization solvent toluene (Merck, Chem. Co.) was distilled twice over sodium. Triethylamine (TEA) (JT Baker, Phillipsburg NJ, U.S.A) was used as dried and purified in the conventional manner. Fourier-transform infrared (FTIR) spectroscopy analysis was performed with a Nicolet Impact 400D Model spectrophotometer (Nicolet Impact, Madison, USA) using $\mathrm{KBr}$ pellets. The spectra were obtained over the wave number range $4000-500 \mathrm{~cm}^{-1}$ at a resolution of $2 \mathrm{~cm}^{-1}$ using an MCT detector with coaddition of 64 scans. Scanning electron micrographs were taken on a JEOL-JXA 840 A SEM (JEOL, Boston, USA). The specimens were prepared for SEM by freeze fracturing in liquid nitrogen and the application of a gold coating of approximately $300 \mathrm{~A}^{\circ}$ with an Edwards S 150 B sputter coater. $\left({ }^{13} \mathrm{C},{ }^{1} \mathrm{H}\right)$ nuclear magnetic resonance (NMR) 
spectra measurements were recorded on a Bruker AV300 MHz spectrometer (4 mm specimen tube).

\section{Cross-linkers Synthesis}

-Type A cross-linker

Dichlorodimethylsilane $8.45 \mathrm{~mL}, 70 \mathrm{mmol}$ was added drop wise to a well-stirred slurry mixture of 2-hydroxyethyl methacrylate $(17 \mathrm{~mL}, 140 \mathrm{mmol})$, anhydrous triethylamine $(20 \mathrm{~g}, 10 \%)$, and $200 \mathrm{~mL}$ fresh distilled toluene at $-5{ }^{\circ} \mathrm{C}$ in a $500 \mathrm{~mL}$ three-necked flask which was dried, purged with nitrogen, and fitted with a mechanical stirrer and a condenser. After the addition, the mixture was then heated under reflux temperature and was continuously stirred for $24 \mathrm{~h}$. The colour of the slushy mixture was white at first, and then it gradually turned slightly yellow. Then, the mixture was cooled to room temperature. The white by-product triethylhydroammonium chloride salt was filtered off quickly to minimize contamination of the product by hydrolysis when the salt was exposed to moisture. The viscous crude product was recovered after removing the solvent using an evaporator. The crude product was then dissolved in chloroform and filtered. The solvent of the filtrate was removed and the residue was finally dried in a vacuum at $50{ }^{\circ} \mathrm{C}$. The final product was viscous pall yellow oil. Yield $=18.32 \mathrm{~g}, 72 \%$.

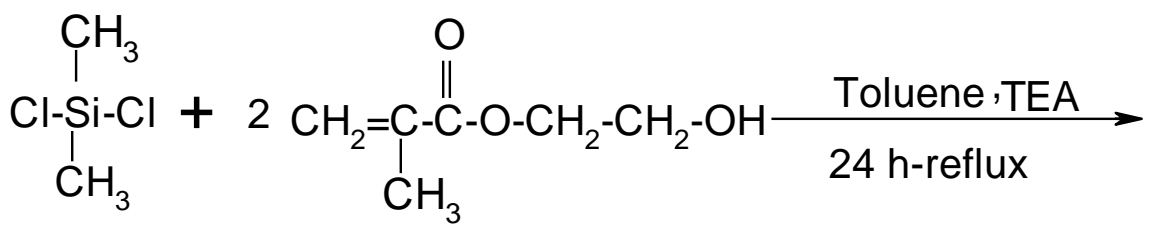<smiles>C=C(C)C(=O)OCCO[Si](C)(C)OCCOC(=O)C(=C)C</smiles>

Scheme 1. Preparation of Type A cross-linker.

-Type B cross-linker

Dichloromethylphenylsilane $10 \mathrm{~mL}, 44.6 \mathrm{mmol}$ was added drop-wise to a well-stirred slurry mixture of 2-hydroxyethyl methacrylate $(12.42 \mathrm{~mL}, 89.2 \mathrm{mmol})$, anhydrous triethylamine $(22 \mathrm{~g}, 10 \%)$, and $200 \mathrm{~mL}$ fresh distilled toluene at $-5{ }^{\circ} \mathrm{C}$ in a $500 \mathrm{~mL}$ three-necked flask which was dried, purged with nitrogen, and fitted with a mechanical stirrer and a condenser. After the addition, the mixture was then heated to a gentle reflux and was continuously stirred for $24 \mathrm{~h}$. The colour of the slushy mixture was slightly yellow at first, and then it gradually turned deep yellow. Then, the mixture was cooled to room temperature. The white by product triethylhydroammonium chloride salt was filtered off quickly to minimize contamination of the product by hydrolysis when the salt was exposed to moisture. The recovery and purification of this product was the same as mentioned above and the final product was viscous deep yellow oil with yield $=13.70 \mathrm{~g}, 61 \%$. 
<smiles>C=C(C)C(=O)OCCO[Si](C)(OCCOC(=O)C(C)(C)C)c1ccccc1</smiles>

Scheme 2. Preparation of Type B cross-linker.

-Type C cross-linker

Dichlorodiphenylsilane $10 \mathrm{~mL}, 33 \mathrm{mmol}$ was added drop-wise to a well-stirred slurry mixture of 2-hydroxyethyl methacrylate $(9.2 \mathrm{~mL}, 66 \mathrm{mmol})$, anhydrous triethylamine $(21.7 \mathrm{~g}, 10 \%)$, and $200 \mathrm{~mL}$ fresh distilled toluene at $-5^{\circ} \mathrm{C}$ in a $500 \mathrm{~mL}$ three-necked flask which was dried, purged with nitrogen, and fitted with a mechanical stirrer and a condenser. After the addition, the mixture was then heated to a gentle reflux and was continuously stirred for $72 \mathrm{~h}$. The colour of the slushy mixture was deep yellow at first, and then it gradually turned brown. The purification was also according to the others which were mentioned above. The final product was viscous brown oil. Yield = $11.52 \mathrm{~g}, 60 \%$.

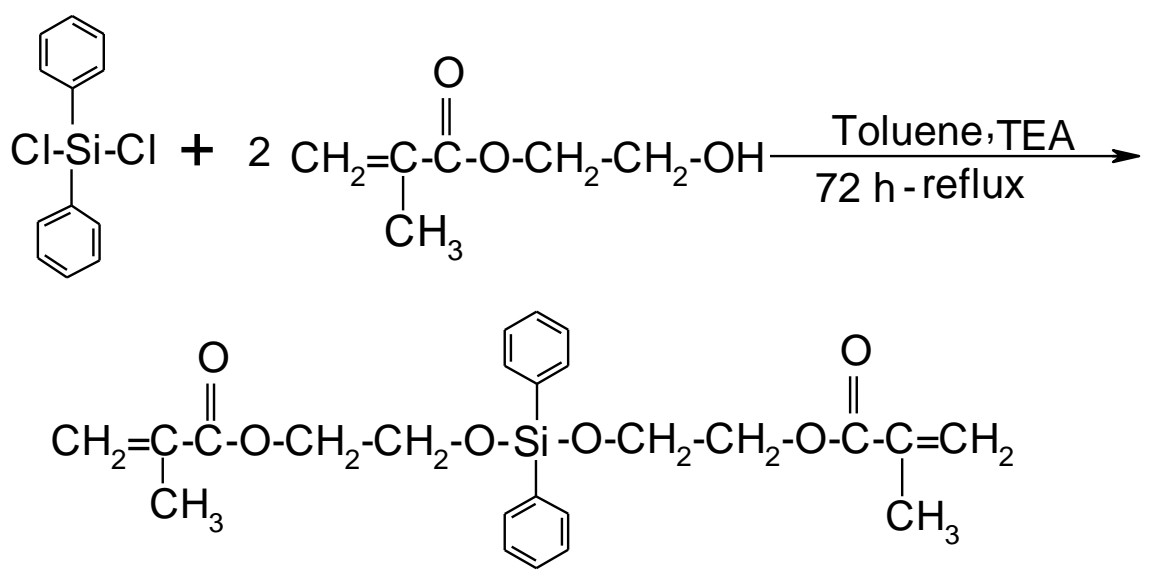

Scheme 3. Preparation of Type C cross-linker.

\section{Polymerization procedure}

Monomer solutions were prepared shortly before use by weighing the required amounts of MMA, toluene, initiator and cross-linkers, Type A, B and C each once through free radical cross-linking copolymerization. Each of the pyrex ampoules with $10 \mathrm{~mm}$ internal diameter and about $70 \mathrm{~mm}$ length was filled with $2 \mathrm{~g}$ of monomer solution. After degassing by four successive freeze-thaw cycles using liquid nitrogen and a reduced pressure of $1.3 \mathrm{KPa}$ the ampoules were torch sealed. The polymerization was initiated by immersing the ampoules in an oil bath maintained at a constant temperature, $70 \pm 0.1^{\circ} \mathrm{C}$ and the reaction was quenched by thrusting the ampoules into liquid nitrogen. 
Tab. 1. Polymerization recipe.

\begin{tabular}{cccccc}
\hline Run & $\begin{array}{c}\text { MMA } \\
\text { molL }^{-1}\end{array}$ & $\begin{array}{c}\text { Cross- } \\
\text { linker } \\
\text { molL }^{-1}\end{array}$ & $\begin{array}{c}\text { Toluene(ml)in } \\
\text { the presence } \\
\text { of } \\
\text { Type A cross- } \\
\text { linker }\end{array}$ & $\begin{array}{c}\text { Toluene(ml)in } \\
\text { the presence } \\
\text { of Type B } \\
\text { cross-linker }\end{array}$ & $\begin{array}{c}\text { Toluene(ml)in } \\
\text { the presence } \\
\text { of } \\
\text { Type C cross- } \\
\text { linker }\end{array}$ \\
\hline 1 & 2.90 & 0.10 & 3.25 & 3.30 & 3.27 \\
2 & 2.85 & 0.15 & 3.15 & 3.23 & 3.20 \\
3 & 2.80 & 0.20 & 3.00 & 3.17 & 3.13 \\
4 & 2.75 & 0.25 & 2.98 & 3.10 & 3.00 \\
5 & 2.65 & 0.35 & 2.80 & 2.99 & 2.92 \\
6 & 2.50 & 0.50 & 2.54 & 2.80 & 2.70 \\
7 & 2.40 & 0.60 & 2.37 & 2.70 & 2.58 \\
8 & 2.25 & 0.75 & 2.10 & 2.50 & 2.36 \\
\hline \multicolumn{5}{l}{$[\mathrm{M}]_{0}=3 \mathrm{molL}^{-1},[]_{0}=1 \times 10^{-3} \mathrm{molL}^{-1}, \mathrm{~T}=70^{\circ} \mathrm{C}$, solvent $=$ toluene } \\
\end{tabular}

It was assumed that the surface-to-volume ratio of the ampoules was high enough to assure isothermal conditions. A typical recipe for the preparation of silicone containing PMMA gels and the process is given in Table 1 and Scheme 4, respectively. The homologous series of polymer gels prepared in this way allowed systematic variation of the silicone containing cross-linker concentrations. The copolymer samples for conversion measurements were obtained by a gravimetric technique. For this purpose, the monomer and solvent were pipetted into a $100 \mathrm{~mL}$ three-neck round-bottomed flask containing a Teflon-coated magnetic stirring bar, and the appropriate amount of cross-linker was then added. To eliminate oxygen from the system, nitrogen was bubbled through the reaction mixture at room temperature for $30 \mathrm{~min}$. Then, the reactor was placed in a thermostated bath at 70 ${ }^{\circ} \mathrm{C}$. In order to detect the end of the induction period, usually a few minutes, small samples were removed from the reactor by means of a syringe and added into methanol. The time of the first appearance of a stable white colour was recorded as $t$ $=0$. Then, samples were taken at various reaction times via syringes and they were precipitated drop-wise into an agitated solution of methanol. The conversion of monomer was determined by drying and weighing the precipitated polymer. The gel point was determined experimentally as the midpoint between the last time at which a soluble polymer was obtained and that at which the mixture was not soluble in toluene.

\section{Extraction of the sol fraction}

Toluene was chosen as the extraction solvent mixture and employed at room temperature. The crude gels, $10 \mathrm{~mm}$ in diameter, were cut into samples of $10-25 \mathrm{~mm}$ length. Each sample was placed in an excess of toluene containing a small amount of 1,4-benzoquinone as an inhibitor, and the solvent was replaced every other day over a period of 3 weeks until no further extractable polymer could be detected. The networks after extraction were carefully de-swollen in a series of toluene/methanol 
mixtures with increasing methanol content. They were then washed several times with methanol and dried at room temperature under vacuum to constant weight. The amount of soluble polymer in toluene solution was determined gravimetrically after evaporation and precipitation in methanol. The weight fraction of gel $\left(W_{g}\right)$ was calculated as

$$
W_{g}=\frac{g}{g+s}
$$

where $\mathrm{g}$ and $\mathrm{s}$ are the weights of extracted network and soluble polymer, respectively.

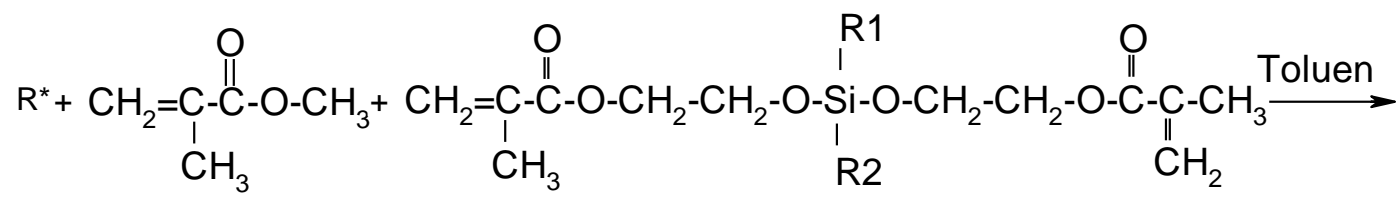

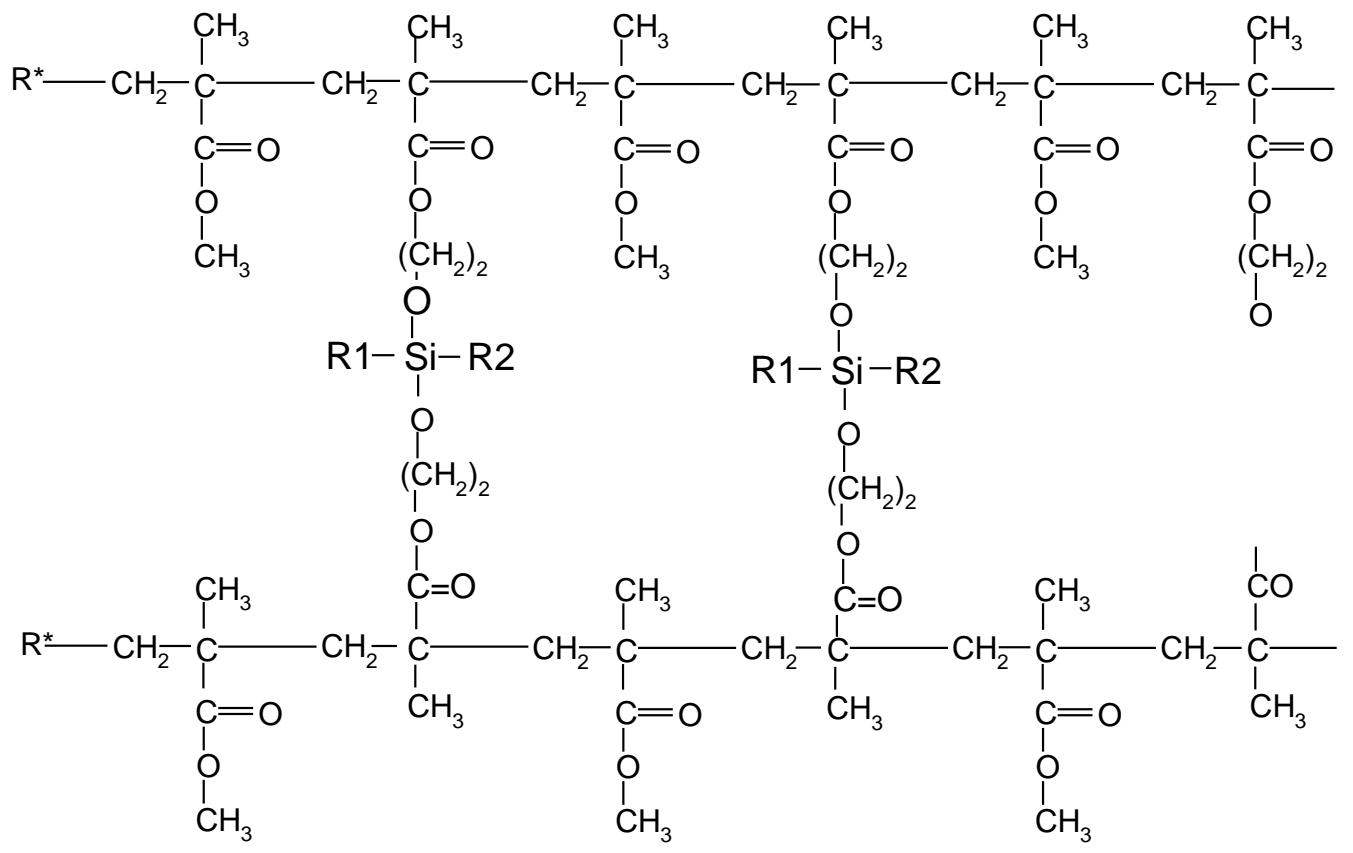<smiles>CC(C)(C#N)N=NC(C)(C)C#N</smiles>

Networks

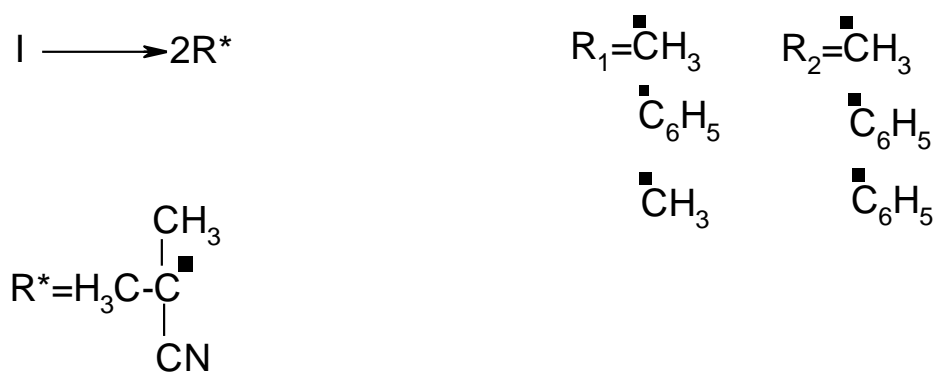

Scheme 4. Silicone containing PMMA gels. 


\section{Swelling measurements}

The swelling measurements were carried out in toluene at room temperature. In order to determine the equilibrium degree of swelling, the networks were immersed in toluene for at least 3 weeks, and the swelling equilibrium was tested by weighing the samples. To achieve higher precision, three measurements were carried out on samples of different weights taken from the same gel. The networks were then weighed in the swollen state and dried, after a solvent exchange with methanol as described above, under vacuum to constant weight. The extent of swelling was characterized by the volume swelling ratio $\left(q_{v}\right)$, which was calculated as:

$q_{v}=1+\frac{\left(q_{w}-1\right) \rho_{\mathrm{P}}}{\rho s}$

Where $q_{w}$ is the ratio of weights of the gel in the swollen state and the dry state, $\rho_{p}$ and $\rho_{s}$ are the densities of polymer and solvent, respectively.

\section{Instruments}

Fourier-Transform Infrared (FTIR) spectroscopy analysis was performed with a Nicolet Impact 400D Model spectrophotometer (Nicolet Impact, Madison, USA) using $\mathrm{KBr}$ pellets. The spectra were obtained over the wave number range $500-4000 \mathrm{~cm}^{-1}$ at a resolution of $2 \mathrm{~cm}^{-1}$ using an MCT detector with co-addition of 64 Scans. Scanning electron micrographs were taken on a JEOL-JXA 840 A SEM (JEOL, Boston, USA). The specimens were prepared for SEM by freeze-fracturing in liquid nitrogen and the application of a gold coating of approximately $300 A^{\circ}$ with an Edwards S 150 B sputter coater.

\section{References}

[1] Fujiki, M.; Kawamoto, Y.; Kato, M.; Fujimoto, Y.; Saito, T.; Hososhima, S.i.; Kwak, G. Chem. Mater. 2009, 21 (12), 2459.

[2] Zhou, L.; Djordjevic, S.S.; Proietti, R.; Ding, D.; Yoo, S.J.B.; Amirtharajah, R.; Akella, V. Appl. Phys. A: Mater. Sci. Processing 2009, 95, 1111.

[3] Nedjah, N.; da Silva, R.M.; Mourelle, L.M.; da Silva, M.V.C. Neurocomputing 2009, 72, 2171.

[4] Zhang, W.Y.; Li, X.X.; Chen, Q.H. J. Clin. Rehabil. Tissue Eng. Res. 2008, 12, 9687.

[5] Haller, D.; Woias, P.; Kockmann, N. Int. J. Heat Mass Transfer 2009, 52, 2678.

[6] Begum, F.; Namihira, Y.; Razzak, S.M.A.; Kaijage, S.; Hai, N.H.; Kinjo, T.; Miyagi, K.; Zou, N. Opt. Laser Technol. 2009, 41, 679.

[7] Shuguang Li.; Yanfeng Li.; Yuanyuan Z.; Guiyao Z.; Ying H.; Lantian H. Opt. Laser Technol. 2008, 40, 663.

[8] Urayama, K. Polym. J. 2008, 40, 669.

[9] Yu, Q.J.; Ma, X.H.; Hao, T.T.; Yu, C.J. Gongneng Cailiao/J. Func. Mater. 2008, $39,946$.

[10] Chen, H.; Tian, X.; Yuan, Y.; Lin, J. J. Appl. Polym. Sci. 2008, 107, 4076.

[11] Liu, Y.R.; Huang, Y.D.; Liu, L. J. Mater. Sci. 2007, 42, 5544.

[12] lizawa, T.; Ishido, T.; Gotoh, T.; Sakohara, S. Polym. J. 2007, 39, 18.

[13] Ding, L.; Hayakawa, T.; Kakimoto, M.A. Polym. J. 2007, 39, 551.

[14] Lee, K.S.; Kim, J.P.; Song, H.S.; Jang, W.G.; Park, Y.S.; Lee, J.S.; Macromol. Rapid Commun. 2006, 27, 1330.

[15] Goda, T.; Ishihara, K. Expert Rev. Med. Devices 2006, 3, 167. 
[16] Saigusa, K.; Suzuki, M.; Shirai, H.; Hanabusa, K. Polym. Prepr. Jpn. 2005, 54, 4180.

[17] Okay, O.; Naghash, J.H.; Capek, I. Polymer 1995, 36, 2419.

[18] Mao, R.; Liu, Y.; Huglin, M.B.; Holmes, P.A. Macromolecules 1995, 28, 6744.

[19] Landin, D.T.; Macosko, C.W. Macromolecules 1988, 21, 851.

[20] Okay, O.; Funke, W. Makromol Chem Rapid Commun 1990, 11, 587.

[21] Okay, O. Makromol Chem 1988, 189, 2217.

[22] Okay, O.; Funke, W. Makromol Chem. 1990, 191, 1573.

[23] Wei, Y.; Yang, D.; Bakthavatchalam, R. Mater Lett. 1992, 13, 261.

[24] Landry, C.J.T.; Coltrain, B.K.; Brady, B.K. Polymer, 1992, 33, 1486.

[25] Cornu, J.F. PhD Thesis (Institut National des Sciences Appliquees, Villeurbanne, 1993.

[26] Saravanamuttu, K.; Du, X.M.; Najafi, S.I.; Andrews, M.P. CanJ Chem, Revue Canadienne de Chimie 1998, 76, 1717.

[27] Tadanaga, K.; Ellis, B.; Seddon, A. J. Sol-Gel Sci. Techn. 2000, $19,687$.

[28] Naghash, J.H.; Dehghan, F.; Massah, A.R. e-Polymers 2008, no. 053

[29] Okay, O.; Kurz, M.; Lutz, K.; Funke, W. Macromolecules, 1995, 28, 2737.

[30] Naghash, J.H.; Okay, O. J. Appl. Polym. Sci. 1996, 60, 979.

[31] Naghash, J.H.; Okay, O.; Yagci, Y. Polymer, 1997, 38, 1187.

[32] Okay, O.; Balimtas, N.K.; Naghash, J.H. Polym. Bullet. 1997, 39, 239.

[33] Bajpai, S.K. Iranian Polym. J. 1999, 8, 239.

[34] Okay, O.; Naghash, J.H.; Pekcan, O. Macromol Theory Simul. 1995, 4, 981.

[35] Naghash, J.H.; Okay, O.; Yagcl, Y. Polym. Bullet. 1996, 37, 213.

[36] Okay, O.; Naghash, J.H. Polym. Bullet. 1994, 33, 672. 